\title{
Rock Mechanics Characteristics Test and Optimization of High-Efficiency Mining in Dajishan Tungsten Mine
}

\author{
Kang Zhao $\mathbb{D}^{1,}{ }^{1,2}$ Shuijie Gu, ${ }^{1}$ Yajing Yan, ${ }^{1}$ Qiang Li, ${ }^{1}$ Wanqi Xiao, ${ }^{1}$ and Guoqing Liu ${ }^{3}$ \\ ${ }^{1}$ School of Architectural and Surveying \& Mapping Engineering, Jiangxi University of Science and Technology, \\ Ganzhou 341000, China \\ ${ }^{2}$ Jiangxi Provincial Key Laboratory of Geotechnical Engineering and Environmental Disaster Control, Ganzhou 341000, China \\ ${ }^{3}$ Changsha Institute of Mining Research Co., Ltd., Changsha, Hunan 410012, China
}

Correspondence should be addressed to Kang Zhao; zhaok_666666@163.com

Received 11 March 2018; Accepted 16 July 2018; Published 13 August 2018

Academic Editor: Wen Wang

Copyright (c) 2018 Kang Zhao et al. This is an open access article distributed under the Creative Commons Attribution License, which permits unrestricted use, distribution, and reproduction in any medium, provided the original work is properly cited.

\begin{abstract}
Rock mechanics test is not only the basis for obtaining the mechanical parameters of rock but also an important means for studying rock mechanics and engineering. In this paper, the uniaxial compression deformation test, Brazilian splitting test, and cornea pressure shear test are carried out for rocks in the Dajishan tungsten mine. The basic mechanical parameters such as uniaxial compressive strength, tensile strength, elastic modulus, Poisson's ratio, and internal friction angle of ore rock and surrounding rock are obtained. Meanwhile, damage characteristics of rock are deeply studied and analyzed under different experimental conditions. According to rock mechanics parameters which are obtained from indoor rock mechanics tests, three design schemes of stope structure parameters are optimized by using the FLAC ${ }^{3 \mathrm{D}}$ numerical simulation software. On the premise of ensuring the stability of the stope structure, the recovery rate of ore and the production capacity of the stope are taken into consideration. It is suggested that the second scheme should be adopted for mines (18 $\mathrm{m}$ for ore room and $7 \mathrm{~m}$ for ore pillar), which provides scientific guidance for the safe and efficient mining of mines.
\end{abstract}

\section{Introduction}

As the main body of underground engineering, the evaluation of the stability of underground structures is based on the stability analysis of engineering rock mass. Rock is also a basic component of rock mass, and its influence on the mechanical properties of rock mass is characterized mainly by its own mechanical properties. In most cases, rock is the decisive factor determining the mechanical properties and mechanical functions of underground engineering rock mass [1]. Mechanical properties of rock refer to the characteristics of stress and strain corresponding to rock under stress and the characteristics of failure, mainly including the strength characteristics, deformation characteristics, and stability characteristics. On the study of rock mechanics properties, domestic and foreign scholars have carried out a large amount of scientific research and achieved fruitful results
[2-6]. Rock mechanics test is one of the most important means to study rock mechanics and engineering. Although the current high technology electronic computing and theoretical analysis have reached a high level, the rock mechanics test is still irreplaceable as a direct solution to the mechanical problems in practical engineering [7]. Through the triaxial compression tests at different temperatures, Zhu Jie grasped the mechanical properties and regularities of soft rock in the Cretaceous strata under different low temperatures and confining pressures, which provided a reliable basis for the design and construction of the mine freezing method in Western China [8]. Based on the experimental data of sandstone, mudstone, and shaly sands, Pourhosseini and Shabanimashcool proposed a theoretical model of weakening the cohesive strength of rocks' constant frictional strength [9]. Based on the results of rock mechanics test, people judge the status of engineering geology and classify and evaluate 
the quality of rock mass $[10,11]$, which provides necessary basic data for mining design and optimization and on-site construction [12].

The Dajishan tungsten mine in Jiangxi Province was discovered and mined in 1918 and has been in mining history for nearly a hundred years now. With annual mining of 300,000 tons of crude ore, mining has gradually entered the deep area. At present, the mine is listed as one of the 40 national demonstration bases for comprehensive utilization of mineral resources [13]. Although there are almost 100 years of mining history, the mine's rock mechanics data is very scarce for various reasons. Mining planning and program design are all based on the experience of engineers and analogy method, lacking the necessary scientific basis, which leads to the occurrence of rock burst, roadway deformation, overlying rock movement, and surface collapse [14]. In order to comprehensively evaluate the rock mass quality and surrounding rock stability of the mine and provide reliable basic data for the design and optimization of the subsequent deep mining plan of the mine, in this paper, the basic mechanical parameters and failure characteristics of ore rock and surrounding rock are obtained according to the uniaxial compression test, Brazilian splitting test, and cornea compression shear test. On this basis, three different stope structural parameters are compared and studied to provide reference for mine safety and efficient mining.

\section{Preparation of Rock Samples}

The collection of experimental rock samples is completed by field sampling. The ore rock is mainly composed of granite, and the surrounding rock is mainly composed of metamorphic sandstone and slate. Processing and preparation of all the samples strictly comply with the requirements of the standards of the International Society for Rock Mechanics [15] and the standard of testing methods for engineering rock mass (GB/T 50266-2013) [16]. After grinding, the cylinder sample size meets the test specifications:

(1) The specimens used for the uniaxial compression set test and the shear strength test are $50 \pm 2 \mathrm{~mm}$ in diameter and $100 \pm 3 \mathrm{~mm}$ in height with a $1: 2$ ratio of specimen diameter to height; the specimens used for the indirect tensile test meet the height diameter ratio of $1: 1$, the height of about $50 \pm 2 \mathrm{~mm}$.

(2) The parallelism of the specimen shall meet the requirement of the flatness error between two end faces which is less than $0.05 \mathrm{~mm}$, and the diameter error is less than $0.3 \mathrm{~mm}$. The end face of the specimen should be kept perpendicular to the specimen axis, and the maximum error value shall not exceed $0.25^{\circ}$.

(3) There is no obvious joint surface and cracks on the specimen surface.

After the preparation of rock sample processing, 90 rock samples were obtained in the laboratory. Rock samples that are not damaged and meet the test requirements are grouped by rock type in an orderly manner, and the rock type, sample size, and sample weight of each sample are also recorded.

\section{Analysis of Rock Mechanics Test Characteristics}

\subsection{Uniaxial Compression Deformation Test Analysis}

3.1.1. Uniaxial Compression Test Results. Samples of the axial wave velocity near the specimen were selected from the prepared rock samples, and the uniaxial compression deformation test was carried out after group numbering. This test is aimed to determine the longitudinal and transverse strain of the specimen under unconfined and uniaxial compressive stress and calculate the rock compressive strength, elastic modulus, and Poisson's ratio. The RMT-150C rock mechanics test system (Figure 1) was used in the test. The loading mode of displacement loading was selected, and the loading rate was $0.002 \mathrm{~mm} / \mathrm{s}$. The YJZ-16 type intelligent digital static resistance strain gauge is used in the deformation test part. The press and the specimen are connected with the cushion block to ensure the uniform force of the specimen.

It should pay attention to keep the loading system and strain collection system in synchronous operation in order to ensure the synchronization of the data. The test results are shown in Table 1.

3.1.2. Uniaxial Compression Deformation Test Analysis. According to the stress-strain curve for the specimen, the deformation process of the sample can be divided into 3 stages. Because of the large number of samples, the stressstrain curves of the K-1 ore rock specimen (Figure 2) are selected for the detailed analysis of the 3 stages.

Stage I. During the initial stage of specimen loading, the stress-strain curve tends to convex downward. The slope of the curve increases slowly with the increase of stress, and the stress increase is obviously smaller than the strain increase, indicating that the specimen is in the stage of compaction. The microcracks, micropores, schistosity, and bedding in the ore rock are quickly closed under external load. From the whole stress-strain curve, it can be seen that the rock deformation at this stage reaches $25 \%$ of the whole deformation stage, while the strength is only $1.3 \%$ of the ultimate strength. The deformation is mainly plastic deformation.

Stage II. With the increase of the external load, the slope of the stress-strain curve is basically at a certain value, which shows a linear relationship. The increase of stress is obviously faster than that of stage $\mathrm{I}$, and the increase of stress is larger than that of strain. It is shown that the load at this stage is mainly carried by the crystalline granular skeleton of the ore rock material and presents the elastic deformation characteristics. This stage belongs to the stage of elastic deformation, and the elastic deformation is the main. 


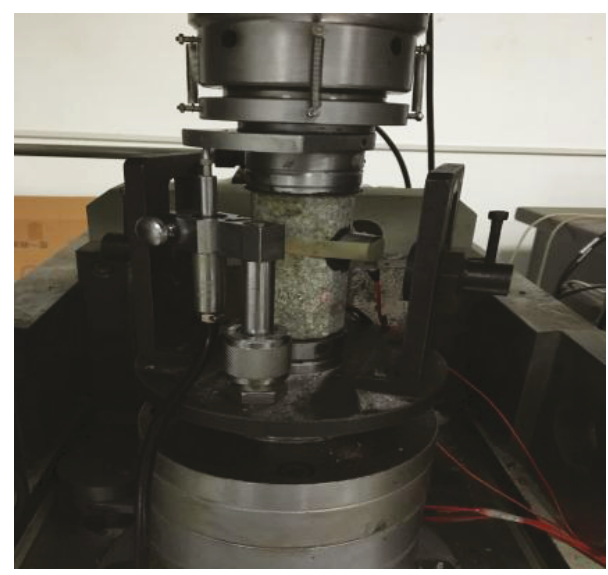

Figure 1: Uniaxial compression test.

Stage III. At this stage, the load has reached the peak strength of the sample. When the strain curve reaches its peak value, the overall trend shows a step-down trend. It shows that the internal structure of the material has been partially damaged after reaching the ultimate load, but it still has some bearing capacity. The overall shape of the ore rock can be basically maintained. The microcracks on the surface of ore rock rapidly expand, extend, and penetrate, eventually forming macroscopic rupture surface until the relative sliding reaches the deformation limit. This stage belongs to the stage of macro damage deformation.

On the above stress-strain curve, there is a straight line elastic deformation stage before the peak of stress. The slope of the approximate straight part is the ratio of the stress to the axial strain, which is called the average elastic modulus of the rock. The data of linear elastic phase of the stress-strain curve of the specimen are linearly fitted by the Origin software. The slope of the fitted curve was the average elastic modulus of the rock. Figure 3 shows the average elastic modulus of K-2 ore rock samples.

The formula for calculating the average elastic modulus $E_{\mathrm{av}}$ is

$$
E_{\mathrm{av}}=\frac{\sigma_{b}-\sigma_{a}}{\varepsilon_{l b}-\varepsilon_{l a}} .
$$

$\sigma_{a}$ is the stress value of the beginning point of the linear segment on the stress-strain relation curve $(\mathrm{MPa}) ; \sigma_{b}$ is the stress value of the end of the linear segment on the stress-strain relation curve $(\mathrm{MPa}) ; \varepsilon_{l a}$ is the axial strain value when the stress is $\sigma_{a}$, and $\varepsilon_{l b}$ is the axial strain value when the stress is $\sigma_{b}$.

By analyzing and sorting out the data of each sample, the elastic modulus of the ore rock and surrounding rock is finally obtained (Table 1).

The measured axial strain and radial strain of the linear elastic phase were introduced into the Origin software for linear fitting (Figure 4). The slope of the fitted curve was obtained as the average Poisson's ratio of the rock samples.
The formula is

$$
\mu_{\mathrm{av}}=\frac{\varepsilon_{d b}-\varepsilon_{d a}}{\varepsilon_{l b}-\varepsilon_{l a}}
$$

where $\mu_{\mathrm{av}}$ is the average Poisson's ratio of the rock. $\varepsilon_{l a}$ is the axial strain value corresponding to the previous $\sigma_{a} \cdot \varepsilon_{l b}$ is the axial strain value corresponding to the previous $\sigma_{b} . \varepsilon_{d a}$ is the radial strain values corresponding to the previous $\sigma_{a} \cdot \varepsilon_{d b}$ is the radial strain values corresponding to the previous $\sigma_{b}$.

3.1.3. Analysis of Failure Mode under Uniaxial Compression. According to the experimental results, it is shown that the failure of the rock after uniaxial compression is more fragmentary, which is characterized by an elastic brittle failure. The release of elastic energy is sudden, accompanied by a burst of sound, most of which are columnar or flaky. A failure mode is parallel to the loading direction along the fracture failure, and the vertical cracks on the surface of rock samples are more developed. After loading, it basically expands along the cracks of the previous specimen (Figure $5 \mathrm{~K}-2$ specimen) until the whole failure. The other is that when the sample is under pressure, compressive stress concentrates on the end of the specimen. In other regions, except for the axial pressure, the radial and circumferential directions are under tension. The cracks on the specimen surface are mainly broken by tensile shear, the rupture surface angle of about $30^{\circ}$ (Figure 5 K-3 sample).

\subsection{Tensile Strength Test Analysis}

3.2.1. Test Method and Process. There are direct and indirect methods for testing the tensile strength of rock. Due to the high requirement for specimen preparation and testing technology, the application of the direct tensile method to a large extent restricts its application. Therefore, the indirect tensile method is usually used in laboratories now. In 1978, the Brazilian splitting method, which was recommended by the international society for rock mechanics to test the tensile strength of rocks in the laboratory, was widely used for its simple experimental operation. The RMT-150C rock mechanics test system is still used in the Brazilian splitting test and the test using a displacement loading method with a loading rate of $0.002 \mathrm{~mm} / \mathrm{s}$. The parameters of the test sample are shown in Table 2.

3.2.2. Test Results and Analysis of Failure Types. The formula for calculating the tensile strength of rock is

$$
\sigma_{t}=\frac{2 P}{\pi D h}
$$

In the form, $\sigma_{t}$ is the rock tensile strength $(\mathrm{MPa}) ; P$ is the specimen failure load $(\mathrm{N}) ; D$ is the cylinder specimen diameter $(\mathrm{mm})$; and $h$ is the cylinder specimen height $(\mathrm{mm})$. In addition to the failure of surrounding rock sample $\mathrm{W}-4$, the test results of others are shown in Table 2.

It can be seen from Table 2 that the maximum tensile strength of surrounding rock is $9.01 \mathrm{MPa}$, and the average tensile strength is $7.21 \mathrm{MPa}$. The maximum tensile strength of ore rock is $4.92 \mathrm{MPa}$, and the average tensile strength is 
TABLE 1: Summary of main lithologic physical and mechanical parameters.

\begin{tabular}{lcccccc}
\hline $\begin{array}{l}\text { Rock } \\
\text { classification }\end{array}$ & $\begin{array}{c}\text { Tensile strength } \sigma_{\mathrm{t}} \\
(\mathrm{MPa})\end{array}$ & $\begin{array}{c}\text { Compressive strength } \sigma_{\mathrm{c}} \\
(\mathrm{MPa})\end{array}$ & $\begin{array}{c}\text { Elastic modulus } E \\
(\mathrm{GPa})\end{array}$ & $\begin{array}{c}\text { Poisson's } \\
\text { ratio }(v)\end{array}$ & $\begin{array}{c}\text { Cohesion force } c \\
(\mathrm{MPa})\end{array}$ & $\begin{array}{c}\text { Internal friction } \\
\text { angle } \varphi\left({ }^{\circ}\right)\end{array}$ \\
\hline $\begin{array}{l}\text { Surrounding } \\
\text { rock }\end{array}$ & 7.21 & 166.99 & 52.85 & 0.22 & 6.9051 & 29.382 \\
Ore rock & 4.08 & 74.26 & 25.44 & 0.23 & 15.427 & 11.497 \\
\hline
\end{tabular}

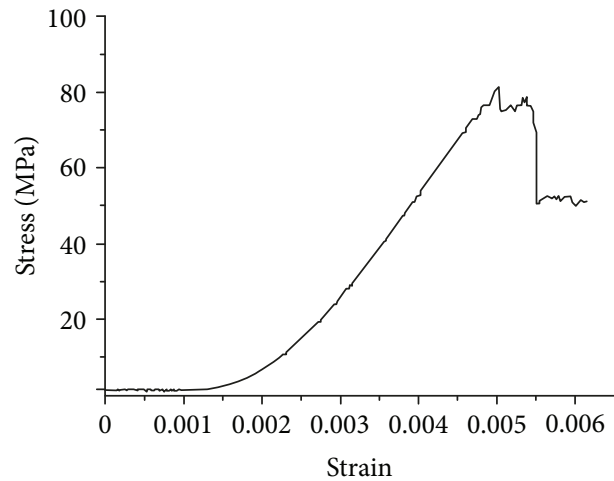

FIgURE 2: Stress-strain curve of ore rock.

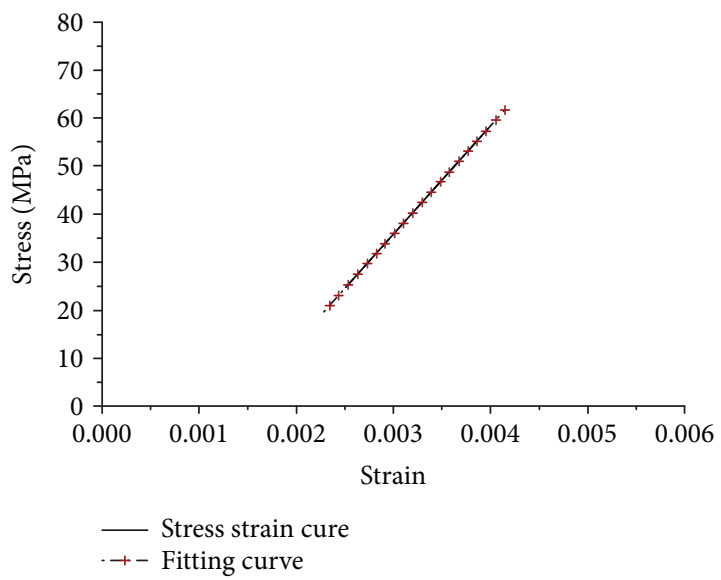

Figure 3: Fitting diagram of elastic modulus of ore rock.

4.08 MPa. In general, the tensile strength of the surrounding rock is larger than the ore rock, which is more conducive to the stability of the mine goaf.

From the failure form of the test specimen, the failure of the specimen is to crack at both ends of the disc specimen then crack through the center of the disc through the whole sample, forming a vertical crack and finally completely split into two semicircles (Figure 6). The destruction shows a straight line of the failure mode.

\subsection{Cornea Pressure Shear Test Analysis}

3.3.1. Test Results. The cornea pressure shear test is a common test method in the laboratory. Parts of the surrounding rock and ore rock with similar wave velocity are

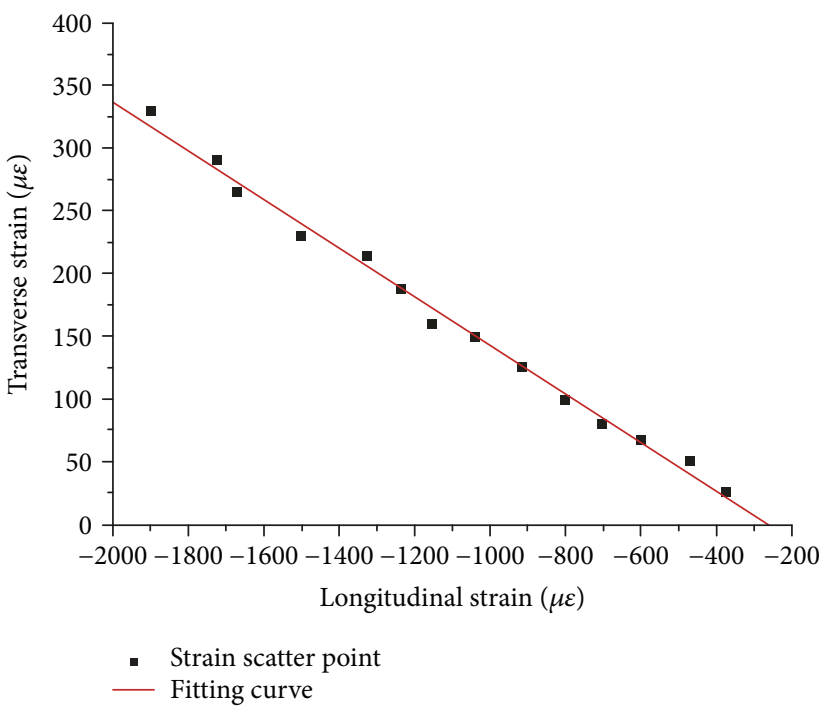

FIgURe 4: Poisson's ratio fitting diagram of K-2 sample.

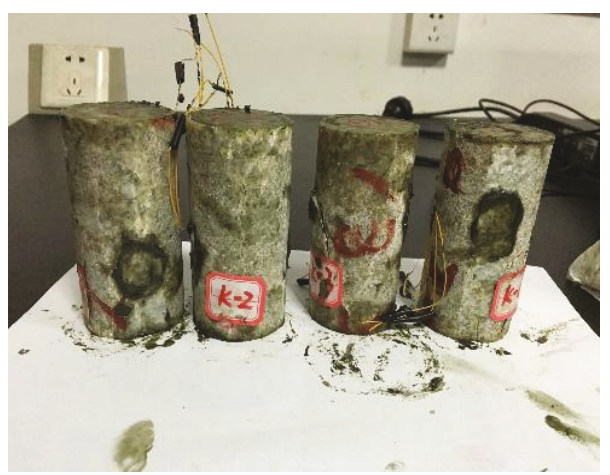

Figure 5: Part of the ore sample failure mode.

selected and grouped for cornea pressure shear test at three angles of $30^{\circ}, 45^{\circ}$, and $60^{\circ}$. Using the RMT-150C type rock mechanics test system, the loading mode of the stroke is selected, and the loading rate is $0.002 \mathrm{~mm} / \mathrm{s}$. The sample information and test results of the shear strength test are shown in Table 3.

Shear failure of the specimen is to overcome the cohesion force and the friction resistance on the shear surface, so the shear strength can be reflected by the cohesive force and the internal friction angle of the rock. The shear stress and normal stress at the time of the failure of the limiting shear test are plotted on the $\sigma-\tau$ stress coordinate system. The test results are fitted to obtain the cohesion force and the internal friction angle (Figures 7 and 8). 
TABle 2: Parameters and results of the tensile strength test specimen.

\begin{tabular}{lccccc}
\hline $\begin{array}{l}\text { Rock } \\
\text { classification }\end{array}$ & $\begin{array}{c}\text { Sample } \\
\text { number }\end{array}$ & $\begin{array}{c}\text { Diameter } \\
(\mathrm{mm})\end{array}$ & $\begin{array}{c}\text { Height } \\
(\mathrm{mm})\end{array}$ & $\begin{array}{c}\text { Tensile } \\
\text { stress } \\
(\mathrm{MPa})\end{array}$ & $\begin{array}{c}\text { Tensile } \\
\text { strength } \\
(\mathrm{MPa})\end{array}$ \\
\hline \multirow{4}{*}{$\begin{array}{l}\text { Surrounding } \\
\text { rock }\end{array}$} & $\mathrm{W}-1$ & 49.52 & 48.40 & 7.33 & \\
& $\mathrm{~W}-2$ & 49.54 & 51.89 & 9.01 & 7.21 \\
& $\mathrm{~W}-3$ & 49.52 & 51.56 & 5.30 & \\
& $\mathrm{~W}-4$ & 49.54 & 48.36 & - & \\
Ore rock & $\mathrm{K}-1$ & 48.60 & 45.40 & 3.89 & \\
& $\mathrm{~K}-2$ & 48.60 & 50.80 & 4.92 & 4.08 \\
& $\mathrm{~K}-3$ & 48.94 & 45.80 & 4.67 & \\
\hline
\end{tabular}

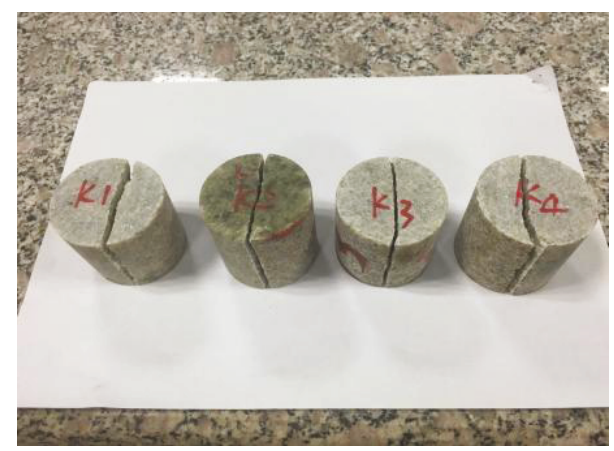

FIGURE 6: Failure mode of some ore rock tensile specimens.

The results of cohesion force and internal friction angle obtained from the rock sample test are shown in Table 4.

3.3.2. Analysis of Shear Failure Types. From Figures 9 and 10, it can be seen that under different conditions of specimen placement, the variation of shear stress-time curve of ore rock and surrounding rock is consistent. The deformation process of samples can be roughly divided into four stages.

Stage I. At the initial stage of specimen loading, the shear stress-time curve is relatively gentle. The microcracks, micropores, schistosity, and bedding in the rock quickly closed under the external load.

Stage II. With the increase of the external load, the shear stress-time curve is approximately linear. There is a stress drop in the curve at this stage, and it may be that one of the structural surfaces in the rock is first cut out, and a stress drop appears.

Stage III. A large stress drop occurs in the shear stresstime curve after the peak shear stress is reached. It is shown that when the shear stress increases to a certain level, the shear deformation of the rock has also been accumulated to a certain extent. There is no damaged part of the rock in the way of instantaneous destruction and with a larger stress drop.

Stage IV. The shear stress-time curve has a larger stress drop after the peak, and the shear stress is not
TABle 3: Angle-moulded shear specimen parameters and test results.

\begin{tabular}{|c|c|c|c|c|c|}
\hline $\begin{array}{l}\text { Rock } \\
\text { classification }\end{array}$ & Angle & $\begin{array}{l}\text { Sample } \\
\text { number }\end{array}$ & $\begin{array}{l}\text { Height } \\
(\mathrm{mm})\end{array}$ & $\begin{array}{c}\text { Diameter } \\
(\mathrm{mm})\end{array}$ & $\begin{array}{c}\text { Peak stress } \\
(\mathrm{MPa})\end{array}$ \\
\hline \multirow{12}{*}{$\begin{array}{l}\text { Surrounding } \\
\text { rock }\end{array}$} & \multirow{4}{*}{$30^{\circ}$} & WJ-1 & 100.40 & 48.94 & 53.506 \\
\hline & & WJ-2 & 99.60 & 49.00 & 55.450 \\
\hline & & WJ-3 & 100.30 & 48.96 & 60.417 \\
\hline & & $\mathrm{WJ}-4$ & 100.06 & 48.94 & 53.048 \\
\hline & \multirow{4}{*}{$60^{\circ}$} & WJ-5 & 100.90 & 49.02 & 66.219 \\
\hline & & WJ-6 & 99.62 & 48.90 & 52.957 \\
\hline & & WJ-7 & 98.64 & 48.98 & 25.293 \\
\hline & & WJ-8 & 100.10 & 49.00 & 54.819 \\
\hline & \multirow{4}{*}{$45^{\circ}$} & WJ-9 & 100.00 & 49.00 & 42.0356 \\
\hline & & WJ-10 & 99.44 & 48.94 & 91.858 \\
\hline & & WJ-11 & 97.02 & 48.84 & 105.659 \\
\hline & & WJ-12 & 99.40 & 48.92 & 38.860 \\
\hline \multirow{12}{*}{ Ore rock } & \multirow{4}{*}{$30^{\circ}$} & KJ-1 & 99.40 & 49.40 & 89.781 \\
\hline & & $\mathrm{KJ}-2$ & 99.00 & 48.80 & 60.732 \\
\hline & & $\mathrm{KJ}-3$ & 99.60 & 48.74 & 57.272 \\
\hline & & $\mathrm{KJ}-4$ & 100.02 & 48.84 & 79.796 \\
\hline & \multirow{4}{*}{$60^{\circ}$} & KJ-5 & 99.40 & 48.70 & 40.234 \\
\hline & & KJ-6 & 99.52 & 48.66 & 58.545 \\
\hline & & KJ-7 & 100.00 & 49.62 & 69.944 \\
\hline & & KJ-8 & 100.02 & 48.60 & 52.173 \\
\hline & \multirow{4}{*}{$45^{\circ}$} & KJ-9 & 99.00 & 48.84 & 87.441 \\
\hline & & $\mathrm{KJ}-10$ & 100.82 & 48.90 & 100.489 \\
\hline & & KJ-11 & 99.40 & 48.84 & 91.471 \\
\hline & & $\mathrm{KJ}-12$ & 100.80 & 48.94 & 74.901 \\
\hline
\end{tabular}

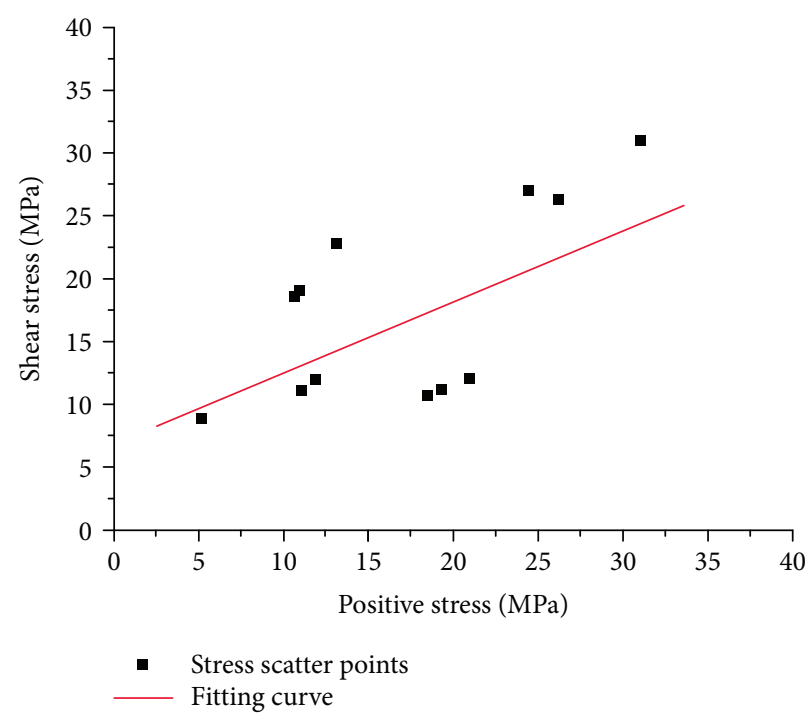

FIgURE 7: The relationship between the shear stress and the positive stress of the surrounding rock.

directly down to the end but shows a gradual downward trend because the shear failure of rock also needs to overcome the friction force on the shear 


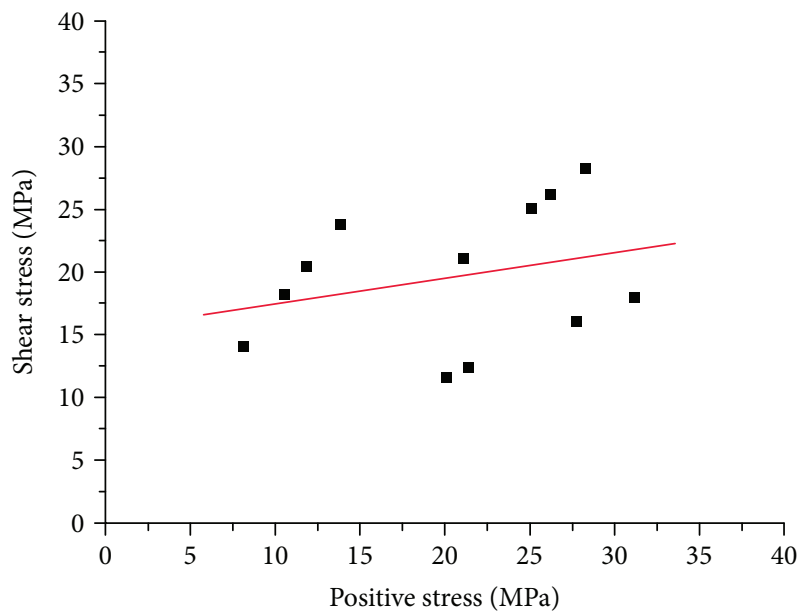

- Stress scatter point

- Fitting curve

FIGURE 8: The relationship between the shear stress and the positive stress of ore rock.

TABLE 4: Calculation results of cohesive force and internal friction angle.

\begin{tabular}{lcc}
\hline Rock classification & Cohesion force & Internal friction angle \\
\hline Surrounding rock & 6.9051 & 29.382 \\
Ore rock & 15.4272 & 11.497 \\
\hline
\end{tabular}

surface. Due to the existence of shear stress on the shear surface, shear failure of rock still has a certain ability to resist shear that there is residual shear strength.

From the failure form of the rock samples, the failure modes are all the main shear planes rupture through the two ends (Figure 11), and there are a small number of local tensile shear cracks near the upper and lower ends. The failure process of the test rock sample is roughly with the increase of the external load, and the broken and intermittent small cracks appear in the shear face position in turn. These cracks continue to grow along the existing direction and form a large crack through each other. After accumulating to a certain extent, the cracks form the whole shear plane and then shear failure.

\section{Stability Analysis of Stope Structure}

4.1. Model Establishment. This numerical simulation combines the mining method used in the mine and takes the 417 middle section as the key research area. The size of the mining block is $25 \mathrm{~m}$ long, $30 \mathrm{~m}$ wide, and $40 \mathrm{~m}$ high. The optimization model of stope structure parameters mainly considers the mining of one ore pillar and two ore rooms. Considering the influence range of mining disturbance is $3 \sim 5$ times of the mining range [17-19], the final model size is $900 \mathrm{~m}$ long, $300 \mathrm{~m}$ wide, and $500 \mathrm{~m}$ high. The

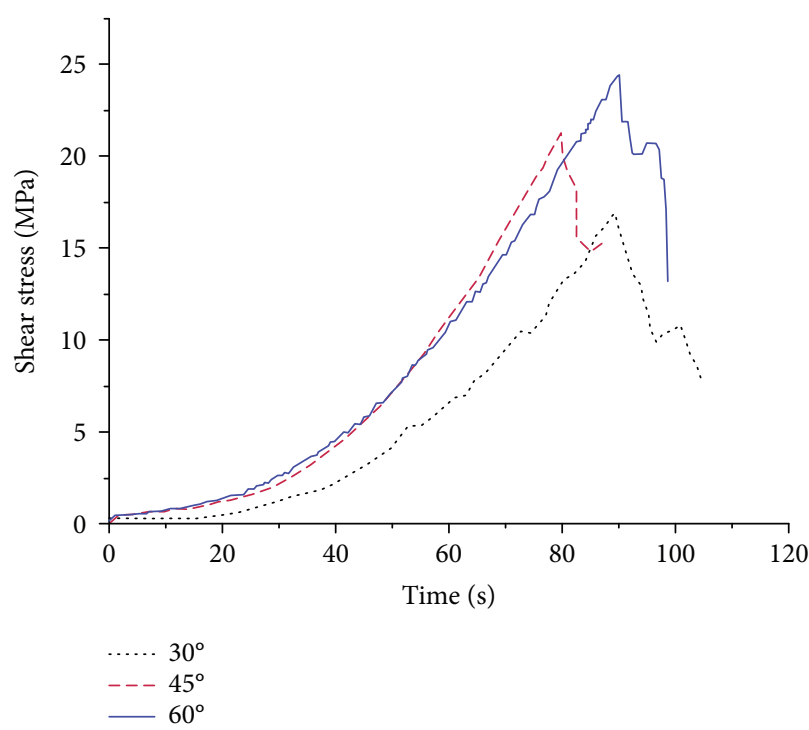

Figure 9: Shear stress-time curves at different laying angle of the surrounding rock.

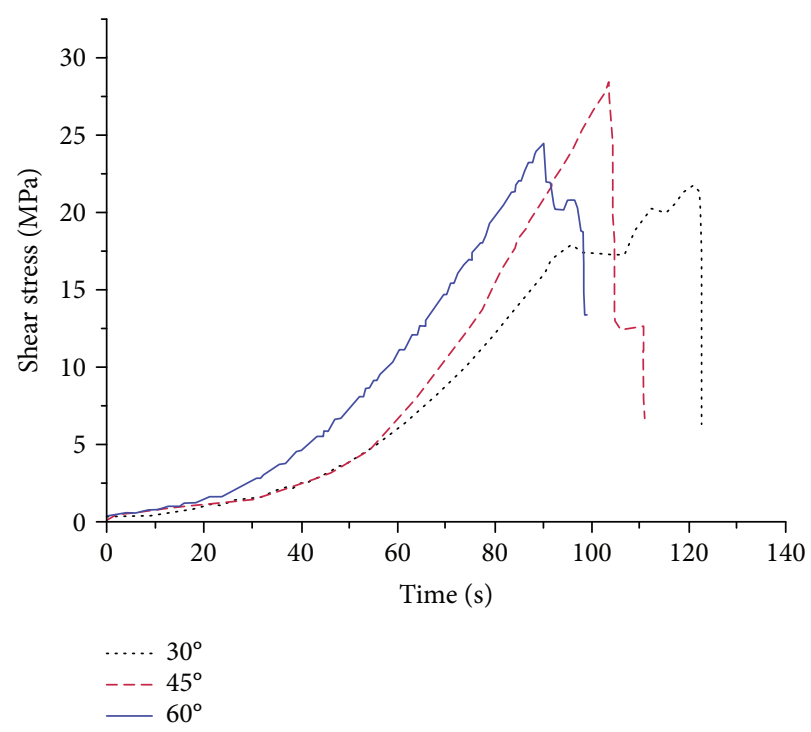

FIgURE 10: Shear stress-time curves at different laying angle of ore rock.

establishment of the model and the division of the grid is shown in Figure 12.

4.2. Model Mechanical Parameters. According to the results of geological survey in the mine, based on the Hoek-Brown strength criterion, combined with other methods and engineering experience, the indoor rock mechanics parameters were reduced after comprehensive evaluation [20-23]. The mechanical parameters used in this simulation are shown in Table 5.

4.3. Disruption Guidelines. Ore rock and surrounding rock of the numerical simulation area can be considered as isotropic elastic-plastic materials. Therefore, the Mohr-Coulomb 


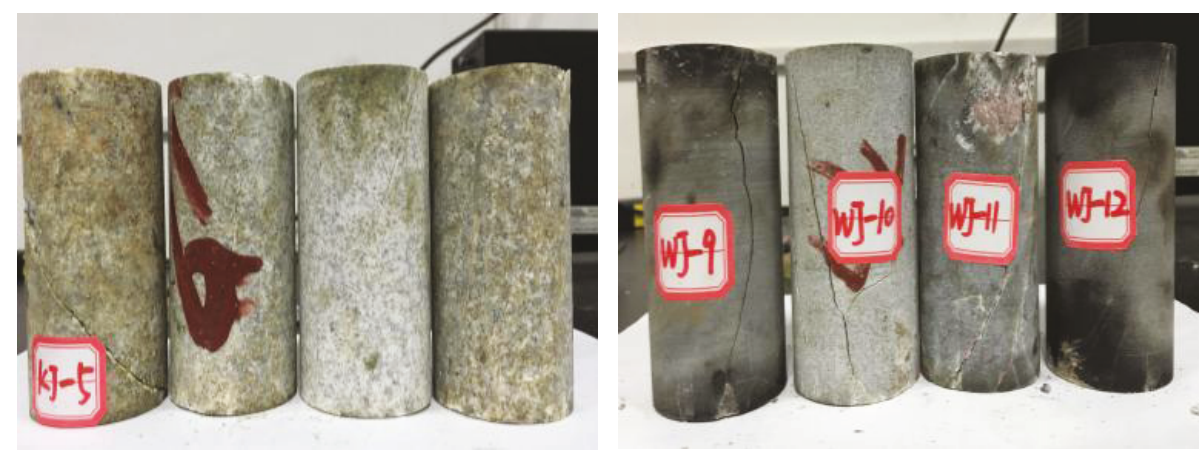

Figure 11: Shear failure mode of surrounding rock and ore rock specimen.

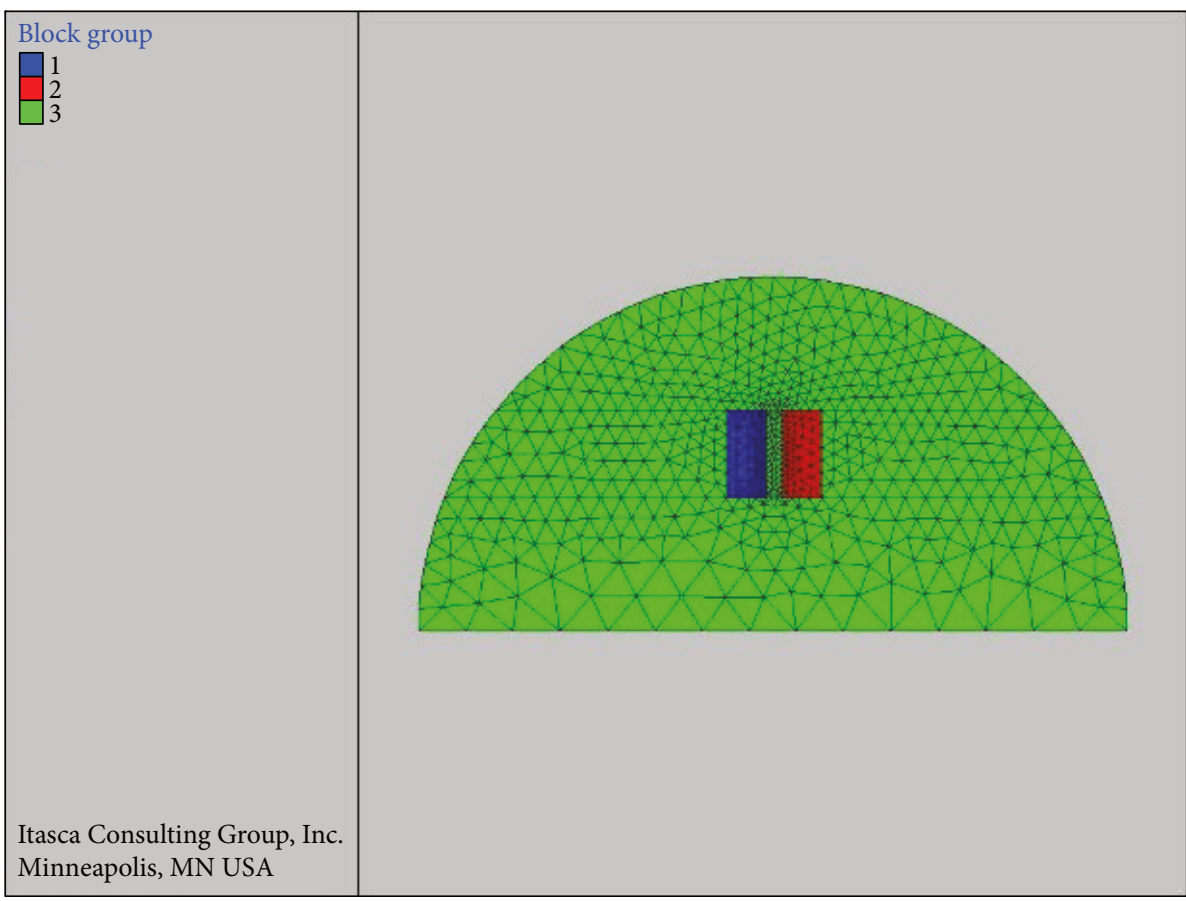

FIGURE 12: Stope model.

TABle 5: Model mechanical parameters.

\begin{tabular}{lcccccc}
\hline $\begin{array}{l}\text { Rock } \\
\text { classification }\end{array}$ & $\begin{array}{c}\text { Tensile strength } \\
(\mathrm{MPa})\end{array}$ & $\begin{array}{c}\text { Bulk } \\
\text { density }\end{array}$ & $\begin{array}{c}\text { Elastic modulus } \\
(\mathrm{GPa})\end{array}$ & $\begin{array}{c}\text { Poisson's } \\
\text { ratio }\end{array}$ & $\begin{array}{c}\text { Internal friction } \\
\text { angle }\end{array}$ & $\begin{array}{c}\text { Cohesion force } \\
(\mathrm{MPa})\end{array}$ \\
\hline $\begin{array}{l}\text { Surrounding } \\
\text { rock }\end{array}$ & 2.4 & 2.75 & 17.6 & 0.22 & 19.58 & 4.6 \\
Ore rock & 1.36 & 2.77 & 6.36 & 0.23 & 7.66 & 10.29 \\
\hline
\end{tabular}

failure criterion can be applied, and its mechanical model is as follows:

$$
f_{s}=\sigma_{1}-\sigma_{3} \frac{1+\sin \varphi}{1-\sin \varphi}-2 c \sqrt{\frac{1+\sin \varphi}{1-\sin \varphi}} .
$$

In the form, $f_{s}$ is the failure discrimination coefficient; $\sigma_{1}$ is the maximum principal stress; $\sigma_{3}$ is the minimum principal stress; $c$ is the cohesion force; and $\varphi$ is the internal friction angle. When $f_{s}<0$, the rock mass is stable; when $f_{s}=0$, it is in the critical state, and when $f_{s}>0$, the rock mass enters the plastic state.

4.4. Stope Structure Parameters Scheme Optimization. According to the actual production situation of the mine and the burial condition of the ore body, three different stope structure parameter schemes were designed for mining simulation. The three schemes are as follows: scheme 1: 


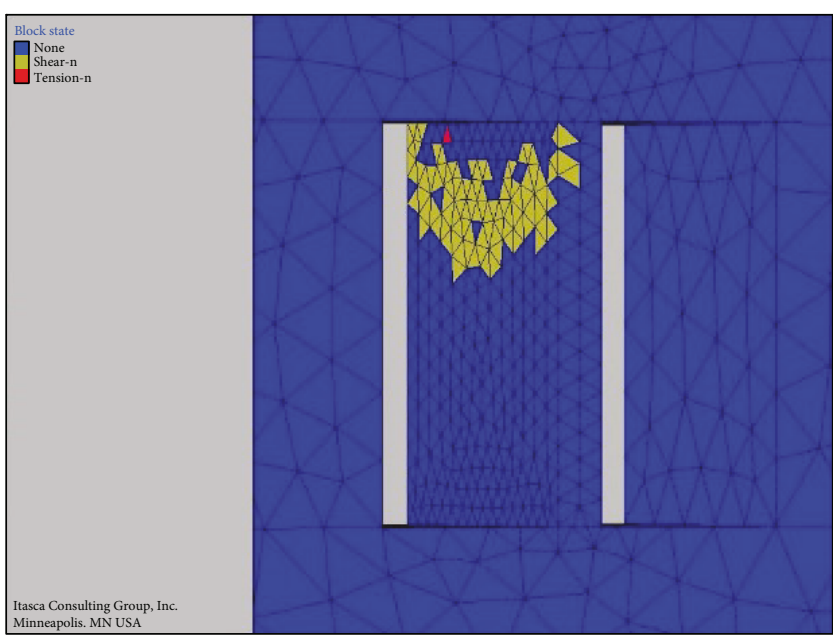

(a) Plastic zone distribution

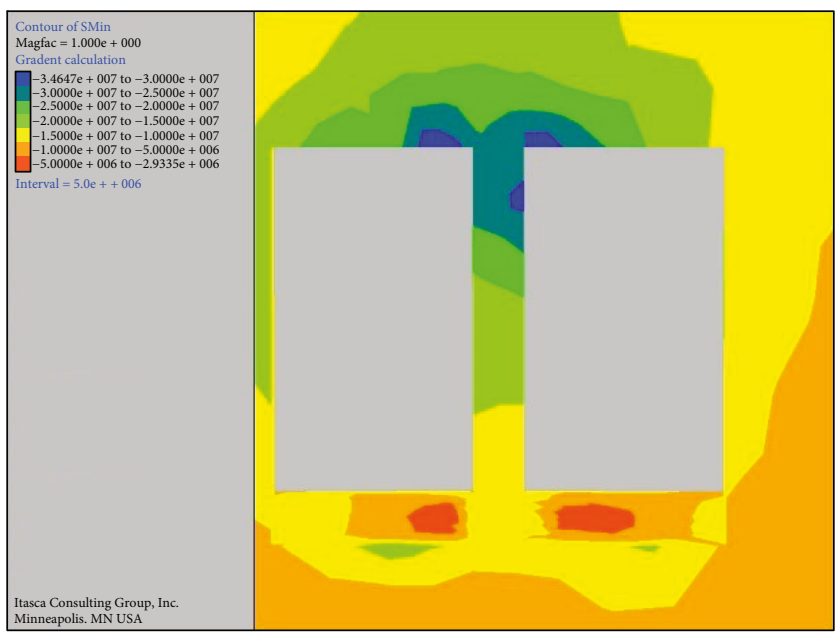

(c) Minimum principal stress

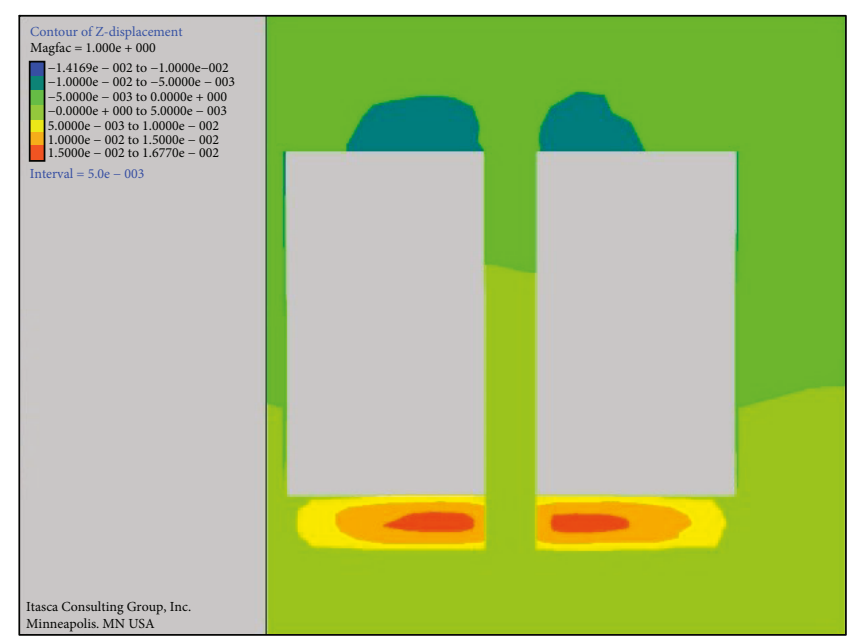

(b) Vertical displacement

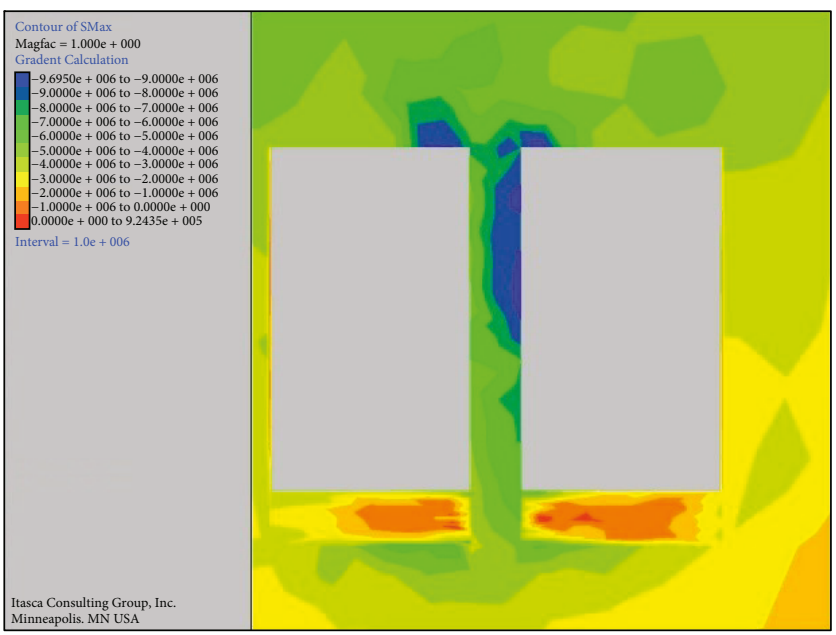

(d) Maximum principal stress

Figure 13: Scheme 1 mining result.

$20 \mathrm{~m}$ ore room and $5 \mathrm{~m}$ ore pillar; scheme $2: 18 \mathrm{~m}$ ore room and $7 \mathrm{~m}$ ore pillar; and scheme 3: $15 \mathrm{~m}$ ore room and $10 \mathrm{~m}$ ore pillar. The FLAC ${ }^{3 \mathrm{D}}$ software was used to simulate the effect of mining an ore pillar and its two side ore rooms on pillar stability. Then the best stope structure parameters were chosen. The material is used in one excavation, and the material is large deformation. Under the same conditions, the three schemes were simulated. Finally, the results of plastic zone distribution, vertical displacement, maximum principal stress, and minimum principal stress after mining were obtained as shown in Figures 13-15.

(1) Plastic zone distribution: by comparing and analyzing the plastic zone distribution map of the three schemes, it was found that the plastic zone of scheme 1 is the most and almost runs through the whole pillar, which indicates that the collapse of stope is likely to happen during excavation, and it does not meet the requirement of stability. The plastic zone of scheme 2 or 3 is smaller, and the size of the plastic zone decreases with the increase of the size of the pillar, which meets the requirement of stability.

(2) Vertical displacement changes: from the vertical displacement cloud diagram of the three schemes, it can be seen that the top and bottom plates all show different degrees of deformation. The maximum displacement appears in the middle part of the top and bottom plates, and the vertical displacement of the three schemes shows a small difference. The roof subsidence is $14.19 \mathrm{~mm}, 8.35 \mathrm{~mm}$, and $6.41 \mathrm{~mm}$, respectively. The upward displacement of the bottom plate is $16.77 \mathrm{~mm}, 13.63 \mathrm{~mm}$, and $9.17 \mathrm{~mm}$, respectively. The maximum displacement of the pillar is $5 \mathrm{~mm}$.

(3) Maximum and minimum principal stress: because the stress set to pull the direction is positive and pressure is negative, the minimum stress is the size of the compressive stress. The maximum compressive stress 


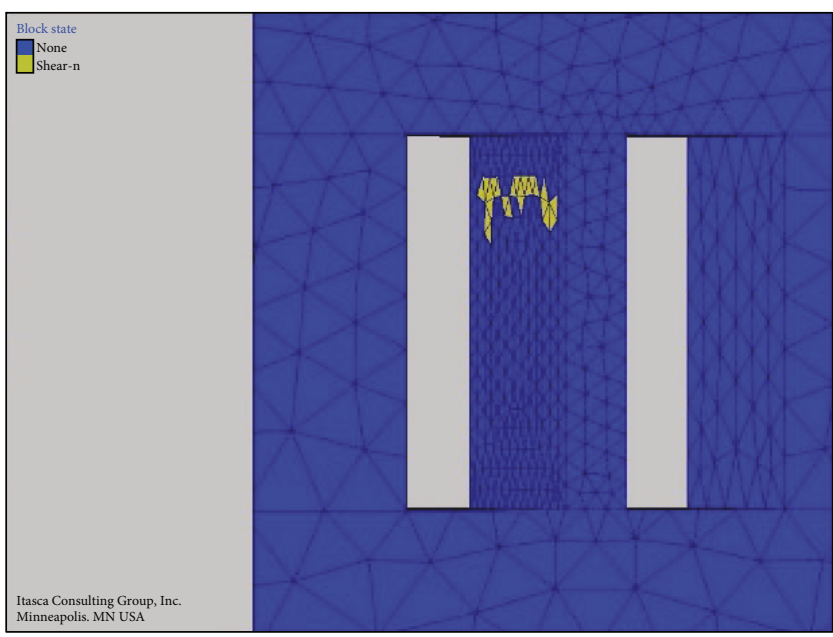

(a) Plastic zone distribution

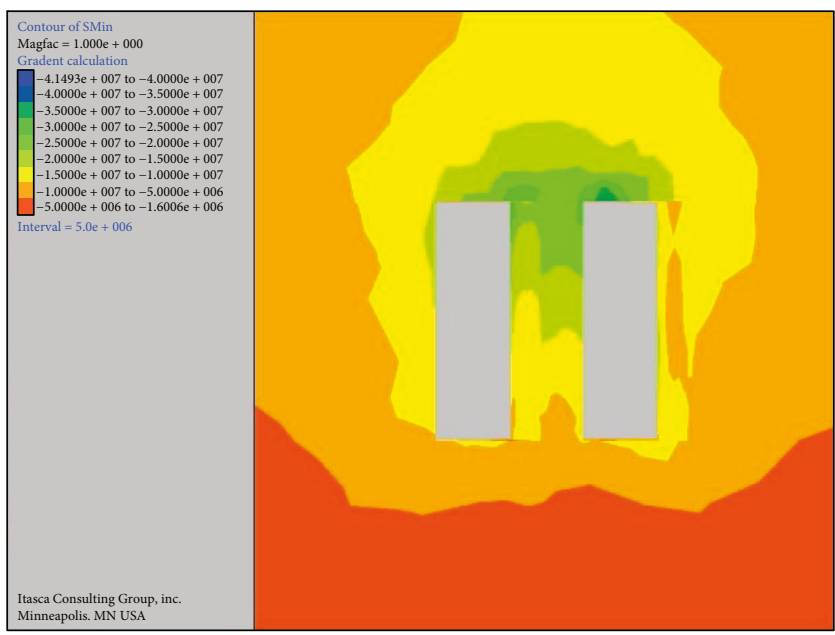

(c) Minimum principal stress

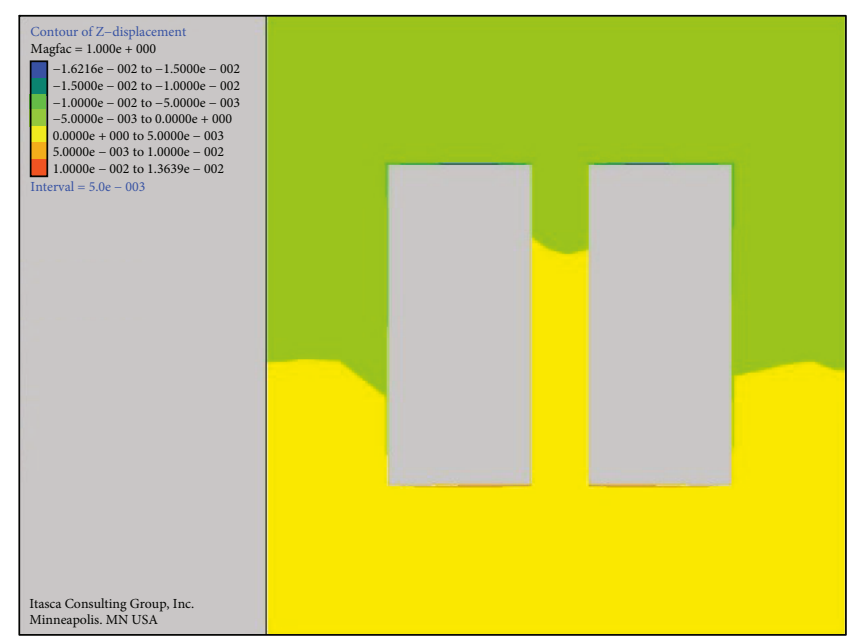

(b) Vertical displacement

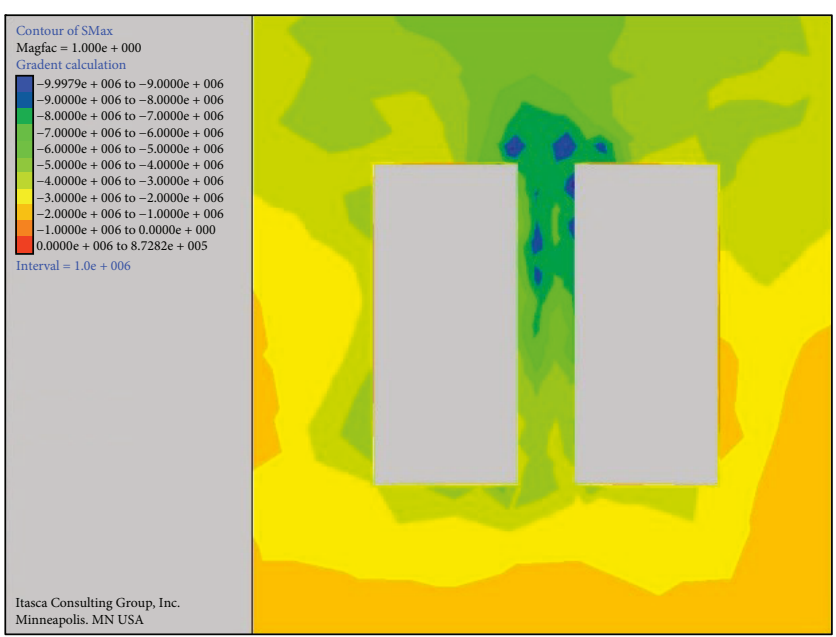

(d) Maximum principal stress

Figure 14: Scheme 2 mining result.

of the three schemes is $34.64 \mathrm{MPa}, 33.36 \mathrm{MPa}$, and 24.39 MPa, which all meet the requirements of compressive strength. The maximum tensile stress of the three schemes is $0.92 \mathrm{MPa}, 0.87 \mathrm{MPa}$, and $0.02 \mathrm{MPa}$, respectively. Although there are some areas in the first scheme and the second scheme that have been devastated, due to the limited area, the stability of the overall structure of the stope cannot be considered affected.

Through the comparative analysis of plastic zone distribution, vertical displacement, and maximum and minimum principal stress characteristics after excavation of the three schemes, the first scheme may lead to instability of stope structure due to the plastic zone penetrating. The third scheme because of the long column is not conducive to increase the production capacity of the stope. Therefore, on the basis of ensuring the safety of stope structure, considering the completion rate of the production plan and economic benefit of the mine, it is suggested to take the second scheme where the ore room size is $18 \mathrm{~m}$, and the ore pillar size is $7 \mathrm{~m}$.

\section{Conclusion}

(1) By uniaxial compression deformation test, the basic mechanical parameters such as uniaxial compressive strength, Poisson's ratio, and elastic modulus of ore rock and surrounding rock are obtained. The compressive strength of ore rock is $74.26 \mathrm{MPa}$, the elastic modulus is $25.44 \mathrm{GPa}$, and the Poisson's ratio is 0.23 . The compressive strength of surrounding rock is 166.99 $\mathrm{MPa}$, the elastic modulus is $52.85 \mathrm{GPa}$, and the Poisson's ratio is 0.22 .

(2) The basic mechanics parameters such as tensile strength, internal friction angle, and cohesion force of ore rock and surrounding rock are obtained by the Brazilian splitting and cornea pressure shear test. 


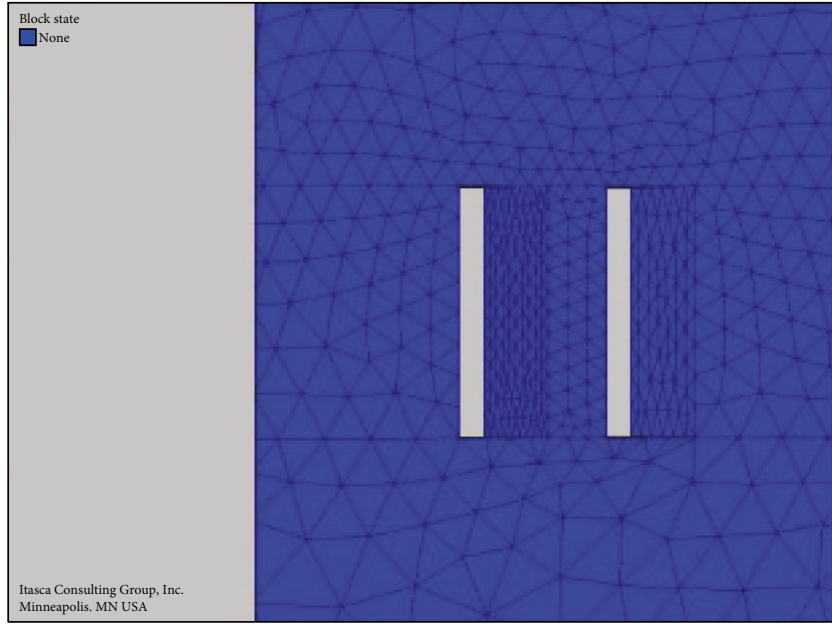

(a) Plastic zone distribution

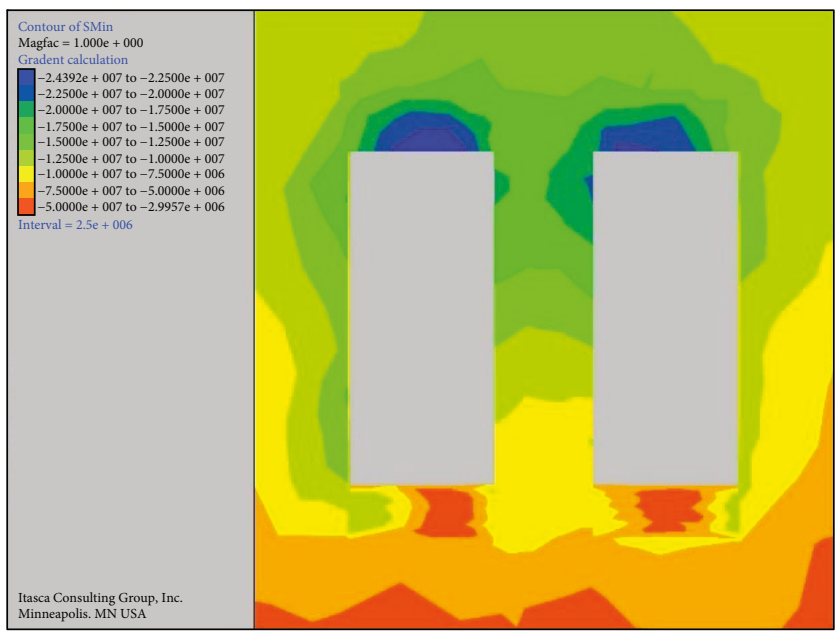

(c) Minimum principal stress

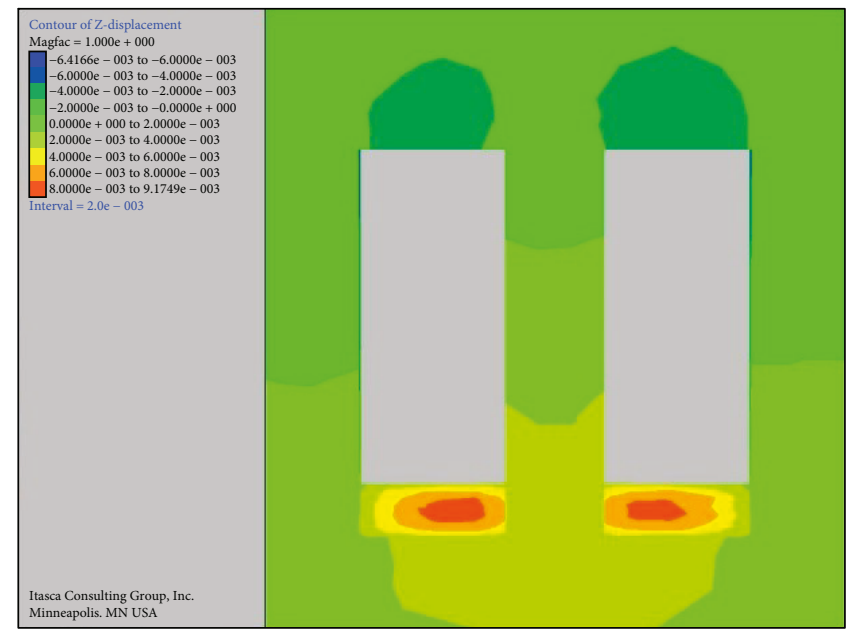

(b) Vertical displacement

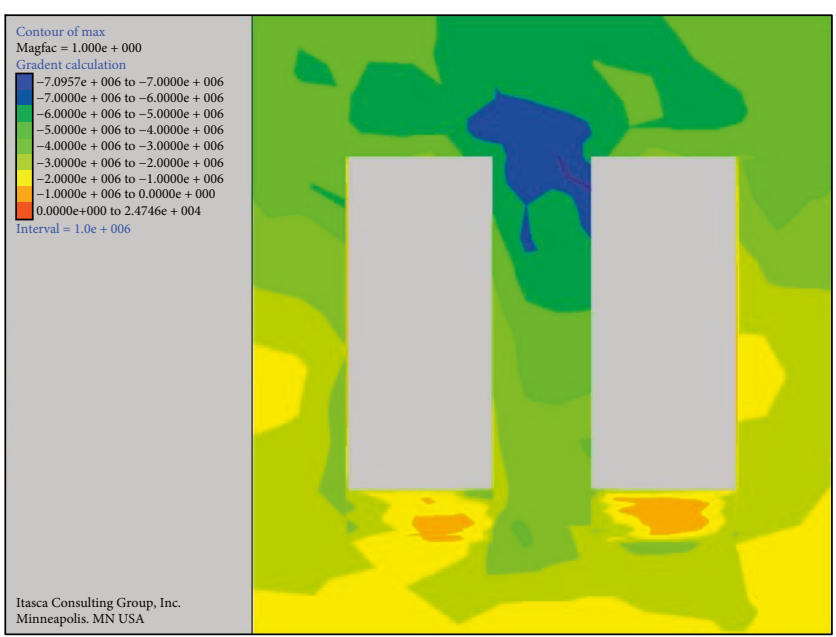

(d) Maximum principal stress

Figure 15: Scheme 3 mining result.

The tensile strength of ore rock is $4.08 \mathrm{MPa}$, the internal friction angle is $11.497^{\circ}$, and the cohesion force is 15.427 MPa. The tensile strength of surrounding rock is $7.21 \mathrm{MPa}$, the internal friction angle is $29.382^{\circ}$, and the cohesion force is $6.9051 \mathrm{MPa}$.

(3) According to the test results of rock strength, both the ore rock and surrounding rock show elastic brittle failure under unidirectional stress state. When the stress reaches the peak, the elastic energy is suddenly released and accompanied by bursts of sound, but the degree is slightly different between them. The surrounding rock performance is the strongest. Therefore, rock burst should be considered in the mining process.

(4) By using the FLAC ${ }^{3 \mathrm{D}}$ numerical simulation software, three kinds of stope structural parameters are simulated and analyzed from aspects of plastic zone, vertical displacement, maximum principal stress, and minimum principal stress. On the basis of ensuring the stable structure of the stope and considering the production capacity of the stope and the recovery rate of the ore, it is suggested to take the second scheme where the ore room size is $18 \mathrm{~m}$ and the ore pillar size is $7 \mathrm{~m}$.

\section{Data Availability}

The data used to support the findings of this study are included within the article. The data supporting the research results can be obtained from the test data table in the paper.

\section{Conflicts of Interest}

The authors declare that they have no conflicts of interest.

\section{Acknowledgments}

The study has been supported by the National Natural Science Foundation (No. 51764013), by the Science and Technology support plan project of Jiangxi Provincial Science and Technology Department (Grant No. 20161BBG70075, 
20143ACG70010), by the Key Research Project of Science and Technology of Jiangxi Provincial Education Department (Grant No. GJJ160592), and by the Undergraduate Innovation and Entrepreneurship Training Program (DC2017-011).

\section{References}

[1] M. F. Cai, Rock Mechanics and Engineering, Science Press, Beijing, China, 2013.

[2] J. Yang, W. Chen, D. Yang, and H. Tian, "Investigating the permeability of marble under moderate pressure and temperature," Geofluids, vol. 2017, Article ID 4126908, 8 pages, 2017.

[3] L. A. N. R. Douma, M. I. W. Primarini, M. E. Houben, and A. Barnhoorn, "The validity of generic trends on multiple scales in rock-physical and rock-mechanical properties of the Whitby Mudstone, United Kingdom," Marine and Petroleum Geology, vol. 84, pp. 135-147, 2017.

[4] W. Zhang, Q. Sun, S. Hao, J. Geng, and C. Lv, "Experimental study on the variation of physical and mechanical properties of rock after high temperature treatment," Applied Thermal Engineering, vol. 98, pp. 1297-1304, 2016.

[5] A. Giwelli, C. Delle Piane, L. Esteban et al., "Laboratory observations of fault transmissibility alteration in carbonate rock during direct shearing," Geofluids, vol. 16, no. 4, 672 pages, 2016.

[6] K. Zhao, H. Y. Zhao, and Q. Y. Jia, "An analysis of rock burst fracture micromorphology and study of its mechanism," Explosion and Shock Waves, vol. 35, no. 6, pp. 913-918, 2015.

[7] H. F. Deng, J. L. Li, C. J. Deng, L. H. Wang, and T. Lu, "Analysis of sampling in rock mechanics test and compressive strength prediction methods," Rock and Soil Mechanics, vol. 32, no. 11, pp. 3399-3403, 2011.

[8] Z. Jie, X. Ying, and L. Dongwei, "Experimental study on mechanical properties of frozen soft rock of cretaceous formation in Bojianghaizi mine," Journal of Jilin University, vol. 46, no. 3, pp. 798-804, 2016.

[9] O. Pourhosseini and M. Shabanimashcool, "Development of an elasto-plastic constitutive model for intact rocks," International Journal of Rock Mechanics and Mining Sciences, vol. 66, no. 1, pp. 1-12, 2014.

[10] J. K. Dong, X. T. Feng, X. W. Zhang, and Z. H. Zhang, "Stability evaluation and parameter optimization on the fractured rock mass around underground stope," Journal of Northeastern University, vol. 34, no. 9, pp. 1322-1366, 2013.

[11] Z. X. Liu and W. G. Dang, "Rock quality classification and stability evaluation of undersea deposit based on M-IRMR," Tunnelling and Underground Space Technology, vol. 40, pp. 95-101, 2014.

[12] S. Shnorhokian, H. S. Mitri, and L. Moreau-verlaan, "Stability assessment of stope sequence scenarios in a diminishing ore pillar," International Journal of Rock Mechanics and Mining Sciences, vol. 74, pp. 103-118, 2015.

[13] Beijing General Research Institute of Mining and Metallurgy, Jiangxi Gannan Tungsten Resources Comprehensive Utilization Demonstration Base Construction of Dajishan Niobium Tantalum Tungsten Ore Development and Utilization Project Feasibility Study Report, Beijing General Research Institute of Mining and Metallurgy, Beijing, China, 2012.

[14] K. Zhao, H. B. Yan, X. Feng, Z. G. Zhu, and L. H. Ye, "Stability analysis of pillar based on energy law," Chinese Journal of
Theoretical and Applied Mechanics, vol. 48, no. 4, pp. 976983, 2016

[15] M. Q. You, Mechanic Properties of Rocks, Geological Publishing House, Beijing, China, 2004.

[16] The Original Ministry of Power Industry of the People's Republic of China, Standard for Test Methods of Engineering Rock Mass (GB/T 50266-2013), China Planning Press, Beijing, China, 2013.

[17] M. A. Perras and M. S. Diederichs, "Predicting excavation damage zone depths in brittle rocks," Journal of Rock Mechanics and Geotechnical Engineering, vol. 8, no. 1, pp. 60-74, 2016.

[18] L. I. You, Y. U. Liang, and L. I. Guanxue, "Determination of disturbed region and critical failure depth of surrounding rock in circular roadway," Journal of Mining and Safety Engineering, vol. 33, no. 5, pp. 795-799, 2016.

[19] Y. J. Shen, G. L. Xu, L. Zhang, and K. J. Zhu, "Research on characteristics of rock deformation caused by excavation disturbance based on Hoek-Brown criterion," Chinese Journal of Rock Mechanics and Engineering, vol. 29, no. 7, pp. 1355$1362,2010$.

[20] S. W. Zhou, S. L. Lin, Q. S. Li, and J. Y. Hu, "Determination of mechanical parameters for suspended rock mass of long span," Journal of Xiamen University, vol. 51, no. 1, pp. 55-59, 2012.

[21] D. M. Lin, Y. J. Shang, F. J. Sun, Y. C. Sun, F. B. Wu, and Z. Q. Liu, "Study of strength assessment of rock mass and application," Rock and Soil Mechanics, vol. 32, no. 3, pp. 837-842, 2011.

[22] O. S. Dinc, H. Sonmez, C. Tunusluoglu, and K. E. Kasapoglu, "A new general empirical approach for the prediction of rock mass strengths of soft to hard rock masses," International Journal of Rock Mechanics and Mining Sciences, vol. 48, no. 4, pp. 650-665, 2011.

[23] Z. Yang, K. P. Hou, K. G. Li, C. L. Zhang, and Y. Cheng, "Determination of mechanical parameters of rock mass from Yunxi Datun Tin Mine," Rock and Soil Mechanics, vol. 31, no. 6, pp. 1923-1928, 2010. 

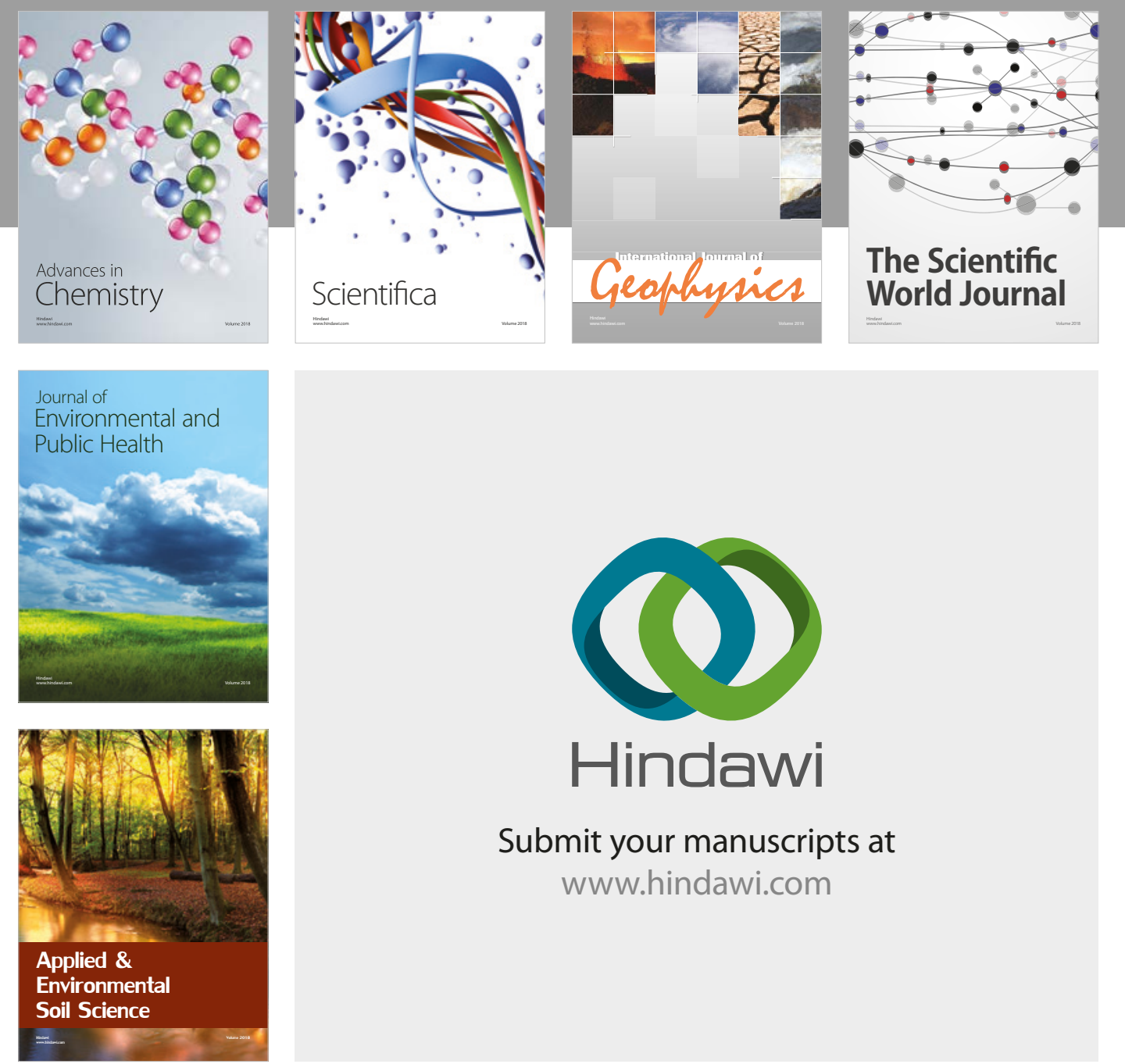

The Scientific

\section{World Journal}
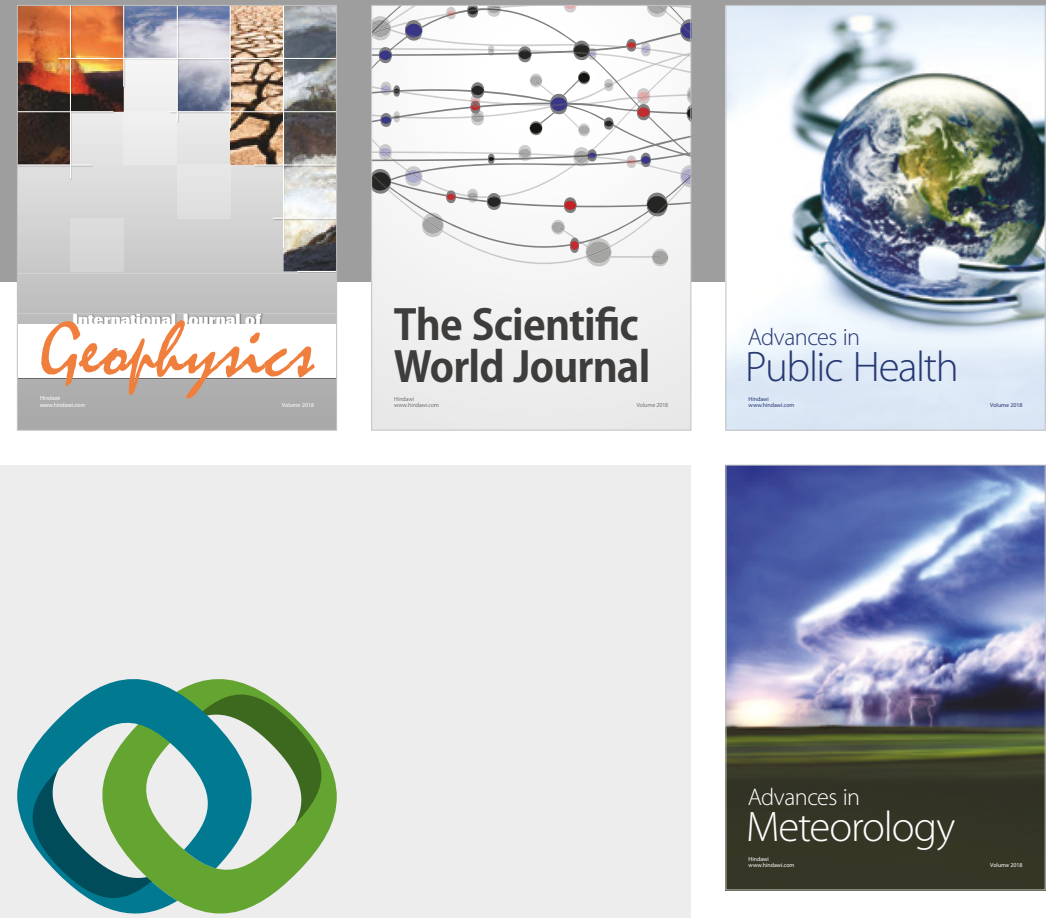

Advan

Public Health

\section{Hindawi}

Submit your manuscripts at

www.hindawi.com
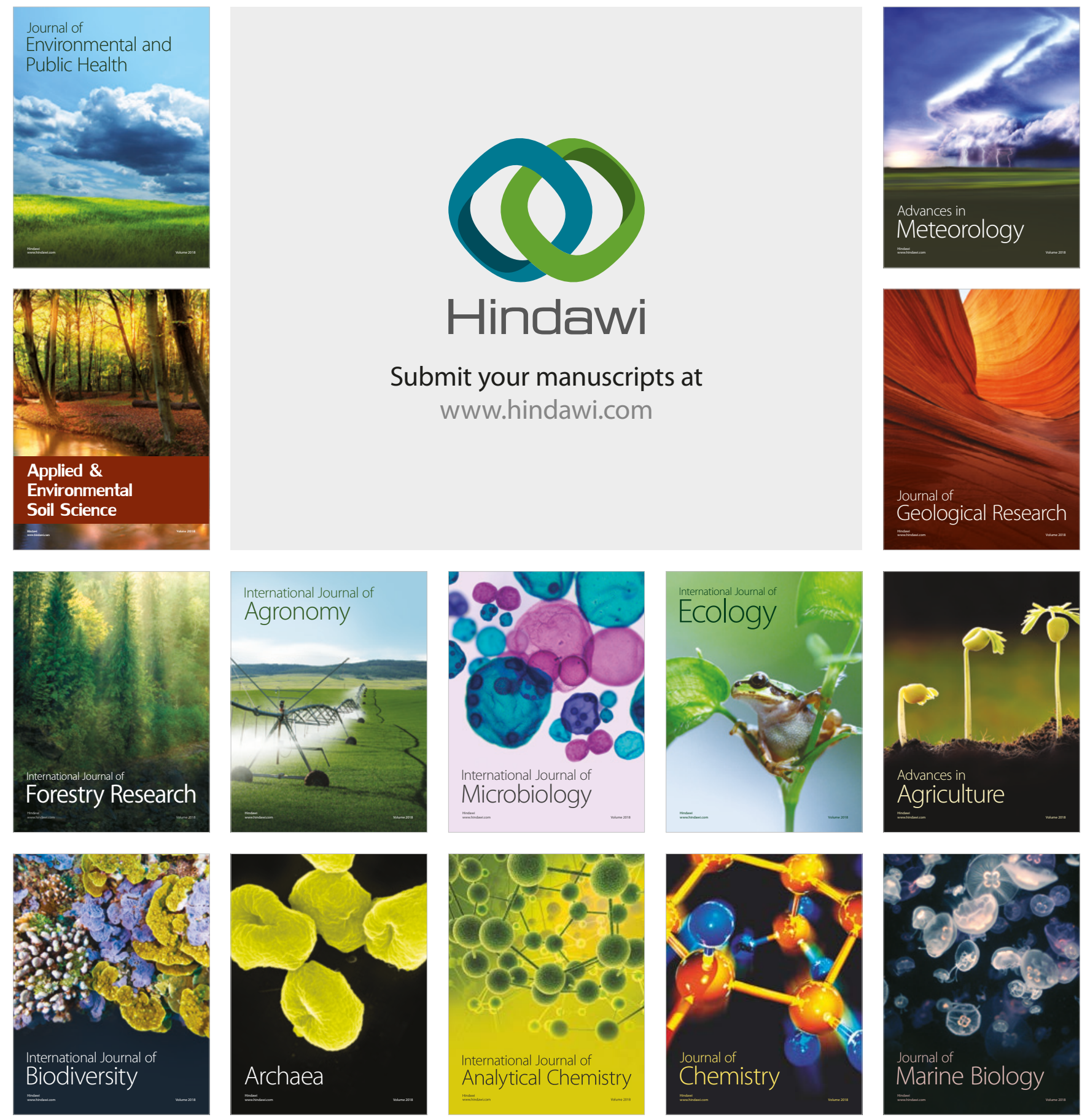